\title{
Online Learning During the Covid-19 Pandemic: How Has This New Situation Affected Students' Oral Communication Skills?
}

\author{
Elena Alcalde Peñalver, Jesús García Laborda \\ University of Alcalá
}

\begin{abstract}
Correspondence concerning this article should be addressed to Elena Alcalde, Pl. de San Diego, s/n, 28801
Alcalá de Henares, Madrid, Spain. E-mail: e.alcalde@uah.es
\end{abstract}

\begin{abstract}
Employing technology has become imperative to accelerate learning efforts and offer methods to enhance interactions between learners, and among learners and tutors. In this paper, we investigate the difficulties faced by learners in learning virtually and, specifically, in English language learning, with a focus on oral communication skills. Research questions of this study are related to the main difficulties that students face to enhance their English oral communication skills. The tools and methodologies that worked best for them for this purpose are also in focus. In the literature we present a review of pertinent studies connected with learning responses in the Covid-19 period and those specifically related to the topic of our study. The methodology used for the study was an exploratory survey research design using a questionnaire to collect the necessary data for our research. Results showed that students highlighted technical problems as some of the main challenges, as well as not feeling completely comfortable in the online learning environment due to the lack of real communication, which also had an impact in the perception of their progress. They also found group video or audio calls to be the most useful tool for communication purposes. The results of this preliminary study are relevant to educational developers and policymakers. They give an understanding of aspects to be considered to improve the efficacy of learners' when it comes to enhancing their English communication skills, such as difficulties regarding interaction or level of satisfaction in an online learning environment.
\end{abstract}

Keywords: communication skills, Covid-19, e-learning, English as a foreign language, technology

\section{Introduction}

People worldwide were stunned after the emergence of Covid-19, which started in the city of Wuhan, China, in November 2019 and then became a global pandemic. Since then, the name of the disease has unfortunately gone from not existing before February 2020 to being part of the daily vocabulary for the vast majority of the world's people (Piller et al., 2020).

The education sector was not immune to these impacts. Following restrictions on physical contact imposed on students and teachers in their schools, the initial educational responses adopted in various countries were school closures and the delivery of online teaching and learning. Presently, faculties have converted their curricula to an online or at least hybrid environment based on a daily or weekly in-person attendance. Even in cases where face-to-face learning has been restored (even partially), the possibility of being able to provide content through an online platform and to be prepared for a totally virtual scenario has also been the norm (Maloney \& Kim, 2020) ${ }^{1}$.

Unfortunately, this transition to the online environment has not generally been a demonstration of good online pedagogy (Dreamson, 2020; Hirsch, \& Allison, 2020²) for many higher education institutions around the globe (Wotto, 2020) in not just a few cases due to teachers' constraints and personal issues (Cutri \& Mena,

\footnotetext{
Maloney, E. J. \& Kim, J. (2020). 15 Fall Scenarios. Inside Higher Education. https://www.insidehighered.com/digital-learning/blogs/learning-innovation/15-fall-scenarios

2 Hirsch, E., \& Allison, C. (2020). Do your materials measure up? remote learning underscores the need for quality curriculum. Learning Professional, 41(4), 28-31
} 
2020; Perrotta \& Bohan, 2020; Romero-Ivanova et al., 2020) which has been generally overcome through the teachers' increase in self-efficacy (Gültekin et al., 2020). Indeed, shifting classes online so quickly became a "double-edged sword" that raised many questions related to privacy, equipment for both teachers and students and teaching and learning methods (Atrey, 20203; Park \& Kim, 2020). At the University of Alcalá (Madrid, Spain), where this study was developed, the situation was no different and all teaching activity had to be adapted to an online environment in which the platform BlackBoard Collaborate started to be used for all the classes that were taking place in the second semester of the academic year 2019-2020 (UAH, 2020a $\mathrm{a}^{4}$. The health situation in Spain improved during the summer and uncertainty prevailed on what the teaching modality would be for the new semester starting in September 2020. Finally, as a preventive measure and also considering the possibilities of having a second wave during the fall, which has actually been the case, a hybrid scenario was adopted and half of the classes have been physically taught with considerable security measures, whereas the rest have been online $\left(\mathrm{UAH}, 2020 \mathrm{~b}^{5}\right)$.

Thus, given this situation, this study aimed to explore the use of technology and its impact on communication skills in learning English as a foreign language during the Covid-19 period specifically at this university. Technology has definitely been a way to reach people, especially learners, during this challenging period in many parts of the world (Jang \& Choi, 2020), but it can also entail some problems when it comes to enhancing communication skills, which should always be at the center of the teaching and learningprocess of foreign languages (Myslihaka, 2016). Therefore, these were the Research Questions (RQ) we aimed to answer with our study: RQ1: What were the main challenges students encountered when communicating in English in an online setting?RQ2:What perceptions do students have of the tools and methodologies that have worked best to enhance their English oral communication skills in English in an online setting? These were the Research Objectives (RO) established in line with the above mentioned RQs:

RO1: To analyse students' main challenges when communicating in English in an online setting.

RO2: To analyse students' perceptions of the tools and methodologies that worked best to enhance their oral communication skills in English.

To answer these questions, first of all this paper opens with a general introduction to the Covid-19 pandemic in which the core issues of the research study are described. The difficulties facing students and teachers regarding online teaching and learning are presented through a literature review of relevant works that relate to teaching, learning and educational responses during the Covid-19 period. The analysis of this literature sheds light on the initial responses and obstacles to the use of technology in this period. Then the methodology used to present some preliminary results on how this situation has affected students' oral communication skills in the English foreign language classroom at the University of Alcalá will be explained. Results are subsequently analysed and contrasted with the theoretical part of the paper. Finally, we conclude with some suggestions and reflections to overcome the outlined difficulties.

\section{Literature Review}

Online education is a way of maintaining undisrupted learning and facilitating flexible learning during the Covid-19 pandemic (Alhabshneh et al., 2020; Zaharah et al., 2020; Reimers \& Schleicher, 20206; Zhang et al., 2020; Basilaia et al., 2020; Kerres, 2020). However, the technological infrastructure has been identified as an obstacle to effective delivery of online education. Alhabshneh et al. (2020) studied the education of dental

\footnotetext{
3 Atrey, S. (2020). Universities beware: Shifting classes online so quickly is a double-edged sword. The Guardian. https://www.theguardian. com/education/2020/may/20/universities-beware-shifting-classes-online-so-quickly-is-a-double-edged-sword

4 UAH (2020a). Medidas de la UAH ante la situación provocada por el Covid-19 [Mesures of the University of Alcalá due to the Covid-19 pandemic]. http://portalcomunicacion.uah.es/diario-digital/actualidad/medidas-de-la-universidad-de-alcala-adoptadas-por-la-situacion-provocada-por-el-covid-19.html

5 UAH (2020b). Nuevo curso académico en la Universidad de Alcalá con carácter semipresencial y medidas de seguridad en todos sus centros [New academic year at the University of Alcalá with a blended-learning scenario and security measures in all faculties]. http:// portalcomunicacion.uah.es/diario-digital/actualidad/nuevo-curso-academico-en-la-universidad-de-alcala-con-caracter-semipresencial-y-medidas-de-seguridad-en-todos-sus-centros

6 Reimers, F., \& Schleicher, A. (2020). A framework to guide an education response to the Covid-19 Pandemic of 2020. OECD. https://www. hm.ee/sites/default/files/framework_guide_v1_002_harward.pdf.
} 
students during the pandemic and reviewed their online learning experiences, tele-dentistry and the significance of implementing dental virtual simulation in preclinical/clinical courses. The study identified that students and teachers faced challenges such as access to online learning equipment, internet connectivity and a lack of technological skills. Zaharah et al. (2020) also examined the impact of the pandemic on e-learning/ teaching activities conducted using technological devices. The study identified difficulties such as the unavailability of online academic systems, internet-connected devices and poor internet connections.

Different countries have been responding to the pandemic in various ways, ranging from a lack of response to social isolation strategies and curriculum redevelopment for online learning (Crawford et al., 2020; Reimers \& Schleicher, 2020; Bao, 2020; Mulenga \& Marban, 2020), which has in some cases been identified as an impediment (Kanwar \& Daniel, 20207). Crawford et al. (2020) studied the higher education digital responses of 20 countries during the pandemic. They claim that students and teachers are liable to face difficulties which include different learning style preferences, a lack of social services and medical attention, and the unavailability of efficient/suitable assessment and evaluation methods due to class sizes.

Reimers \& Schleicher (2020) proposed an education response to support the exchange of knowledge at all levels of educational governance during the outbreak. However, they identified difficulties such as the unavailability of parents/guidance to aid virtual learning and teaching at home, the absence of communication between teachers and parents to ensure learning is aligned with the curriculum, and inadequate relationships with students. Bao (2020) studied the initiation of online teaching in higher education using Peking University's online education, noting that while teachers lacked preparation, virtual teaching experience, and assistance from educational technology personnel, students also lacked learning materials, self-discipline and a good learning environment at home.

Moreover, online education has an influence on the wellbeing or psychological nature of students (Sahu, 2020; Smart Learning Institute of Beijing Normal University, 2020 $)$. Sahu (2020) analysed the impact of the outbreak on the education and mental health of students and teachers and identified challenges such as a lack of resources/infrastructure, the inability to monitor students during online tests to avoid cheating, a lack of internet/accommodation facilities, resilience (Mays, 2020 ${ }^{\circ}$ ) and traumatic stress (Gross, 2020). Alhabshneh et al. (2020) posited that students faced challenges such as class sizes, feelings of disconnectedness, a loss of teacher immediacy and interpersonal interaction. Reimers \& Schleicher (2020) and Zhang et al. (2020) suggested that students often lacked the motivation, strategies, resilience, learning abilities and skills to enhance individual and online learning, and they had poor emotional health and complex home-environments for studying.

When it comes to language learning, since the outbreak of the pandemic various research studies have been published on the many different issues that the process of adapting to this new situation has raised. However, none of them have as their main focus the impact of the pandemic on oral communication skills. Regarding the learning process, Wargadinata et al. (2020) described in their paper the shift in Arabic learning at their higher education institution, which was transformed from a personal-cultural approach to an instrumental-functional approach. In this case, students were more likely to use the video function through the Whatsapp application and have peer-discussion activities. At a more psychological level, MacIntyre et al. (2020) studied language teachers' coping strategies during the Covid-19 conversion to online teaching and showed that this situation had indeed resulted in high levels of stress for them, which undoubtedly also has a consequence on the students' learning process. The report of the British Council $(2020)^{10}$ also focused on teachers' needs during the pandemic and highlighted that they perceived online teaching to be more tiring for them as well as for students compared to physical interaction. It also took them longer to plan their lessons and they believed that the success of

\footnotetext{
7 Kanwar, A., \& Daniel, J. (2020). Report to commonwealth education ministers: From response to resilience. Commonwealth of Learning. https://search-proquestcom.ezproxy.uned.es/docview/2458995621?accountid=14609

8 Smart Learning Institute of Beijing Normal University. (2020). Handbook on facilitating flexible learning during educational disruption: The Chinese experience in maintaining undisrupted learning in Covid-19 outbreak. UNESCO International Research and Training Centre for Rural Education.

9 Mays, T. (2020). Towards more resilient schooling: Possible models for the future. Commonwealth of Learning. https://search-proquestcom.ezproxy.uned.es/docview/2458993339?accountid=14609

${ }^{10}$ British Council (2020). A survey of teacher and teacher educator needs during the Covid-19 pandemic April-May 2020. https://www. teachingenglish.org.uk/sites/teacheng/files/covid19-teacher-teacher-educator-survey.pdf
} 
online learning depended on students' self-discipline. Some recommendations were also provided in this report (p. 5), such as giving teachers opportunities to share learning, provide training and support on how to teach remotely, provide clear guidance on how to choose platforms or develop material in combination with television, radio and other 'distance learning' methods. Another study published by Sayer \& Braun (2020) on the impact of Covid-19 remote learning on English learners in the United States showed some socioeconomical disparities due to the lack of preparation of some students to move to remote learning. Moreover, there were also some communication challenges in this situation, since the online resources that were provided lacked the necessary meaningful social interaction for language learning despite significant efforts in the second language classroom (Altavilla, 2020). Another study also found that participation in a discussion in an online setting also depended on how comfortable students felt when speaking in English, and some found it more difficult to communicate complex ideas through texting or commenting functions and they preferred conversations with their teachers and peers in person (Williams \& Carhill-Poza, 202011). In this regard, Hartshorn and McMurry (2020) revealed, among other findings, that the pandemic was more challenging for students than for teachers and it affected their oral communication skills since they experienced less language development for speaking than for writing. The Education Development Center (2020) ${ }^{12}$ also stated that teaching English online can be a struggle for both teachers and learners since many of the strategies used do not translate into virtual environments, especially with the implications that this situation has for the enhancement of oral communication skills. As for effective tools for teaching English online during the pandemic, Destianingsih and Satria (2020) conducted a study in which they found that students mainly preferred the use of Google Classroom compared to WhatsApp and Zoom. Another study conducted by Altam (2020) revealed that students felt enthusiastic using social media to learn English during this period and that they felt their language skills improved. In this same line of research, Amuthan Krishnan et al. (2020) conducted a study to find out students' perceptions regarding the use of blogs and forum for English learning during the pandemic. The results show that students were eager to use these resources and that it contributed to the overall acquisition of language skills. However, they all agreed that they would prefer this to be combined with face-to-face classes.

\section{Materials and Methods}

\section{Research Design}

An exploratory survey research design was chosen for this study using a questionnaire to collect the necessary data for our research. This method is exploratory since it aims to describe students' perceptions in an issue that has not been deeply examined to date, to shed some light and initiate further research in this respect. Moreover, the research was cross-sectional since the data for the study was collected once and a mixed-method approach was used with quantitative (numerical) as well as qualitative (students' answers) data.

\section{Participants}

Participants were students from the Education Degree at the University of Alcalá who had a course of English as a second language which requires upon completion a B2 level of language competence (19 participants out of 24 students that were part of the class in total). The rest of students of the class did not participate because they did not follow the process of continuous assessment in which class participation is required, and thus they only take the final exam. All participants were aware of the aims and objectives of the study and accepted to participate voluntarily.

\section{Instruments}

The survey used (Appendix 1) was adapted from two other existing ones that aimed to study issues in English language learning (British Council, 2020) and perceptions of students in higher education institutions during the Covid-19 pandemic (Demuyakor, 2020). It was subsequently validated by two Spanish university professors

\footnotetext{
${ }^{11}$ Williams, T. P. \& Carhill-Poza, A. (2020). For many immigrant students, remote learning during Covid-19 comes with more hurdles. The Conversation. https://theconversation.com/for-many-immigrant-students-remote-learning-during-covid-19-comes-with-more-hurdles-144633

${ }^{12}$ Education Development Center (2020). How is the Pandemic Affecting English Learners? https://www.edc.org/how-pandemic-affecting-english-learners
} 
and anonymously distributed through a Google Form link to the participants.The reason why the questionnaire was used is because it is an instrument that allows the researcher to collect a considerable volume of data easily and quickly (Fraenkel \& Wallen, 2019) and, in general, it is not an instrument that requires a lot of time on the part of the participants, which is essential for them to be encouraged to participate and respond in the most reliable and precise possible way. Results were analysed in a descriptive way, since this is considered a preliminary research study to set the basis for further research in this topic in the future. This was done using the numerical data from the survey as well as the qualitative answers added by respondents.

\section{Results and Discussion}

In this section we will analyze the results obtained through the distribution of the survey in order to answer the RQs stated in the introduction of the paper. First of all, regarding the tools that students perceived as the best to enhance their communication skills in English, group video or audio calls (which can take place via Zoom or Skype for example) were perceived as the most useful ones $(88,9 \%)$, followed by online games and materials (50\%) and mobile phone messaging and app messaging (33,3\%) and social media (27,8\%). Compared to what studies cited in the theoretical part of our study stated (Destianingsih \& Satria, 2020; Amuthan Krishan et al., 2020), in which other tools were used that were not specifically oriented towards the enhancement of oral skills, in this case the mentioned resources were more focused on the communication process in the online classroom. However, according to students' responses, teachers mainly used group video or audio calls, but social media and gamified online content were not among their most used tools. Regarding their justification for these options, students highlighted the lack of interaction, the feeling of having someone listening to you and motivation as key aspects of the tools they find more useful for them. Some of these reasons were mentioned in the studies conducted by Reimers \& Schleicher (2020) and Zhang et al. (2020) as factors which can be problematic when teaching online. However, in this case students perceived them as part of the justification of why they thought that the tools they chose could be beneficial for their learning.

When asked about how easy or difficult they found communicating with their partners in class, Figure 1 shows that the highest percentage of participants had an average perception about it.

\section{Figure 1}

Respondents' Perceptions on How Easy or difficult it Was for Them to Communicate with Their partners in Class

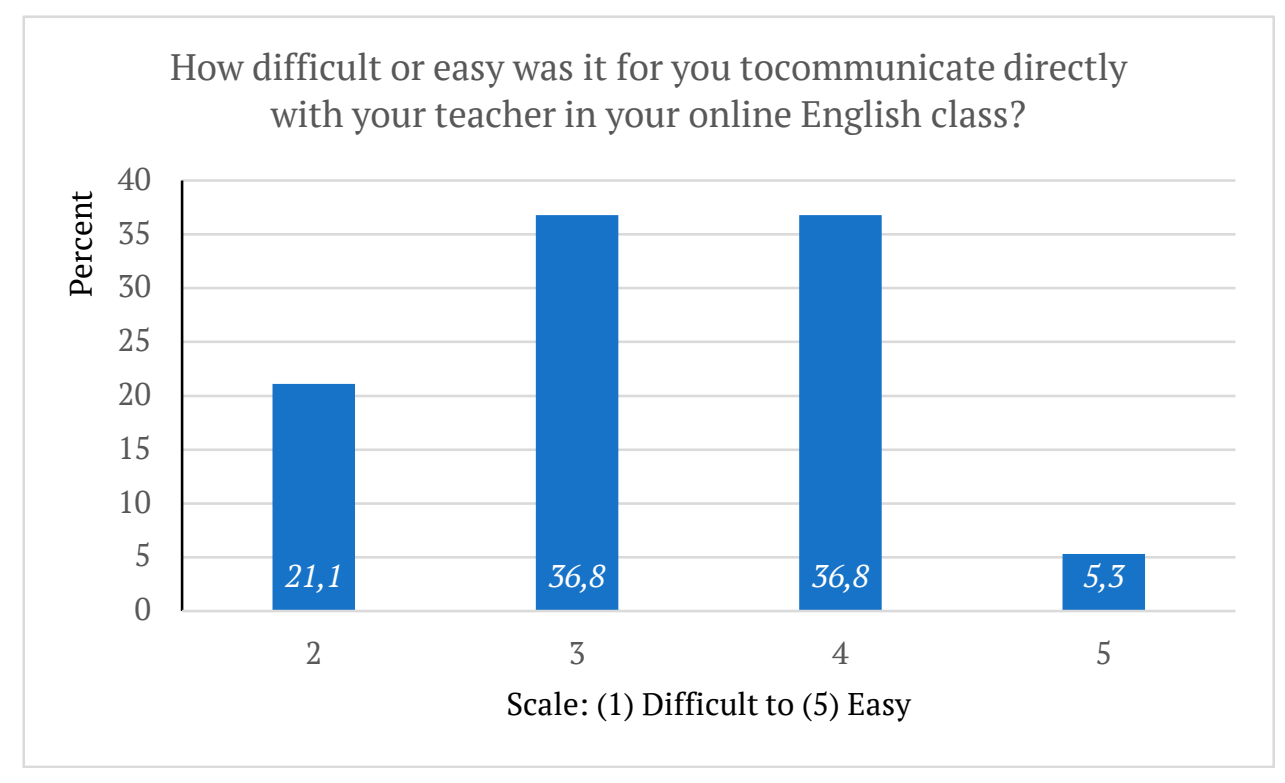

However, when asked about this interaction with their teachers, results showed a higher difficulty (Figure 2), which was also highlighted by Reimers \& Schleicher (2020). 


\section{Figure 2}

Respondents' Perceptions on How Easy or Difficult it Was for Them to Communicate with Their Partners in Class

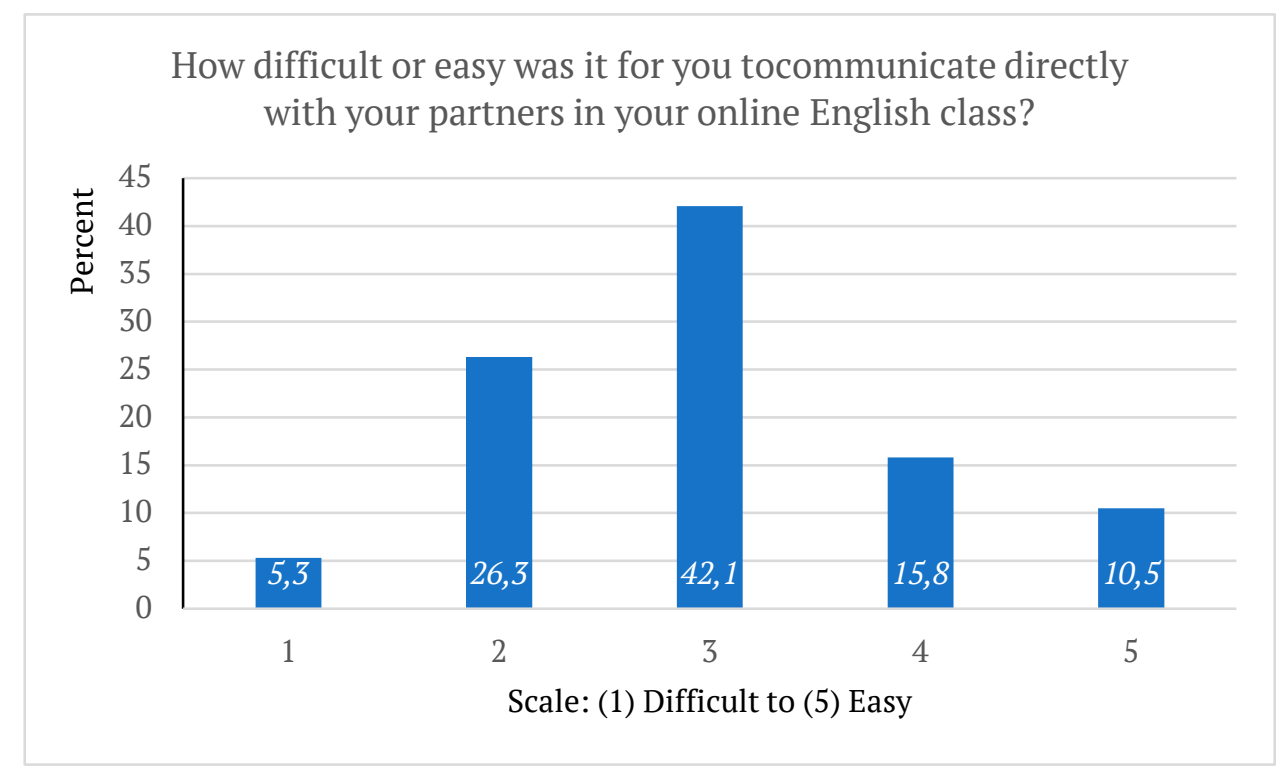

Regarding their confidence, results showed that $42.1 \%$ of participants had an average perception about how difficult or easy it was to communicate directly with their partners in their online English class (Figure 3).

\section{Figure 3}

Respondents' Level of Confidence when Speaking in an Online Class

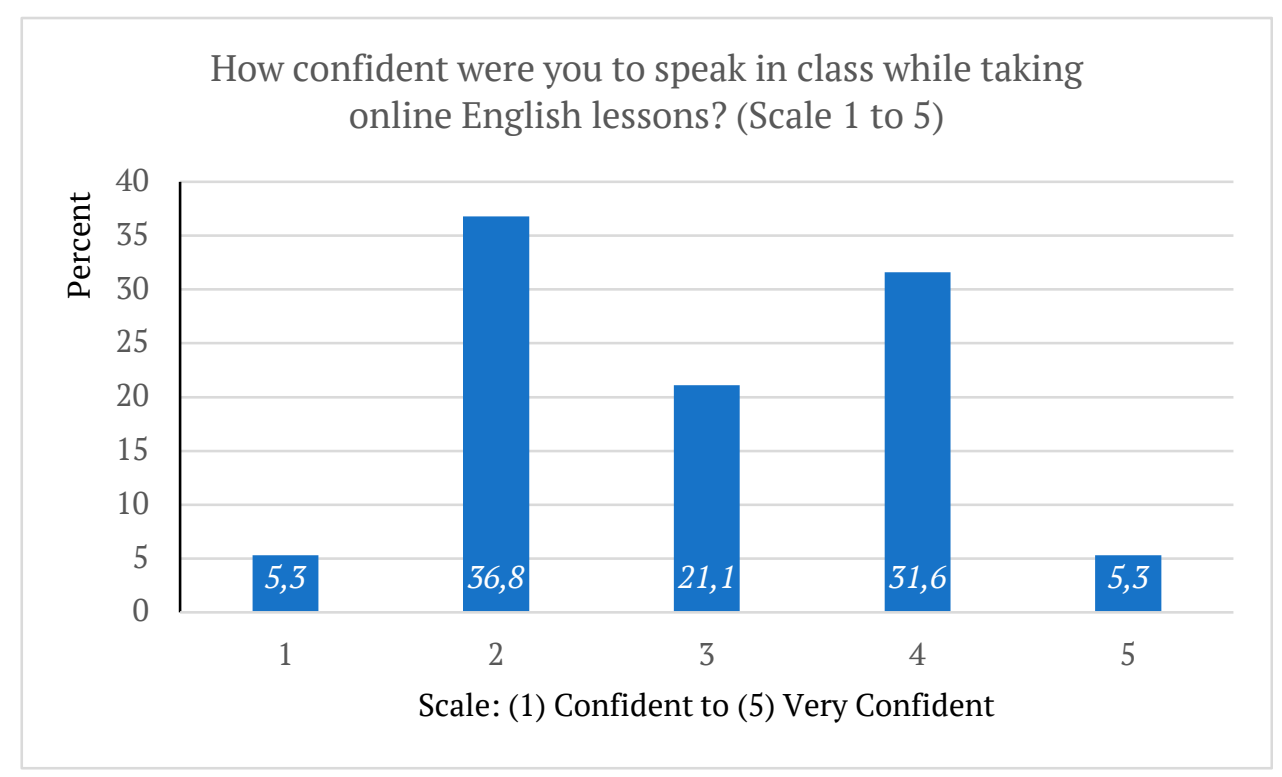

In this sense, the main challenges that students faced while communicating in English were related to technical problems (83,3\%), the artificial environment (50\%), feeling shy (50\%) and too many distractions at home (44.4\%). The technological challenges seem thus to be a general factor of discomfort for the learning process, as stated by previous studies (Zaharah et al., 2020).

When students were asked about their level of satisfaction with their oral communication skills in English after taking an online class, none of them felt completely satisfied and the highest percentage of students showed a low level (Figure 4). 
Figure 4

Respondents' Level of Satisfaction with Their Oral Communication Skills in English after Taking an online Class

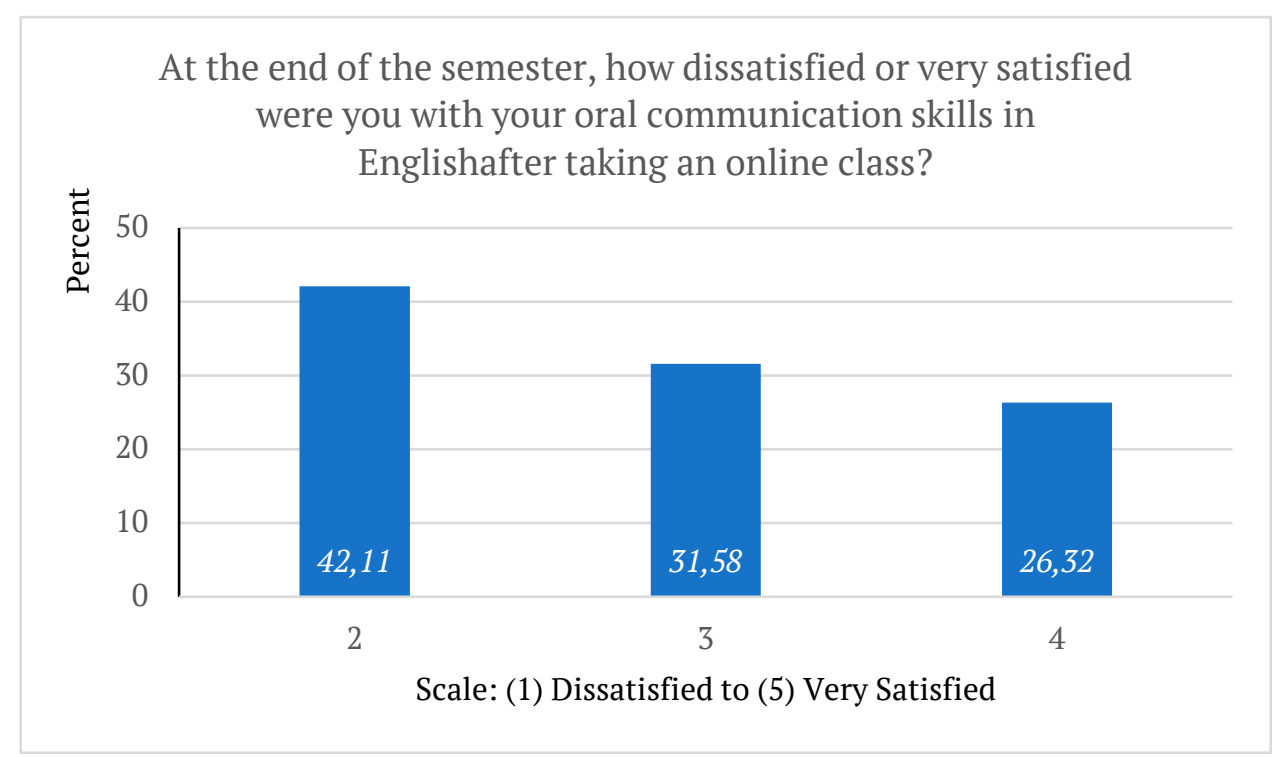

Students' main concerns in this regard were related to connection problems and the lack of "real communication", which did not allow them to speak as much as in a face-to-face class. This is in line with the results by previous studies (Alhabshneh et al., 2020; Sahu, 2020).

When asked if they felt they had missed out on some learning opportunities to enhance their communication skills, the lowest percentage corresponds to those who answered negatively, which shows that most of the students felt as they were not getting as much as they would in a physical class (Figure 5). This is also in line with the results of the study published by Hastshorn \& McMurry (2020).

\section{Figure 5}

Respondents' Perception about Having Missed Out on Some Learning Opportunities to Enhance their Communication Skills

Did you feel that whith English lessons you missed out on some learning opportunites to enchance your communications skills?

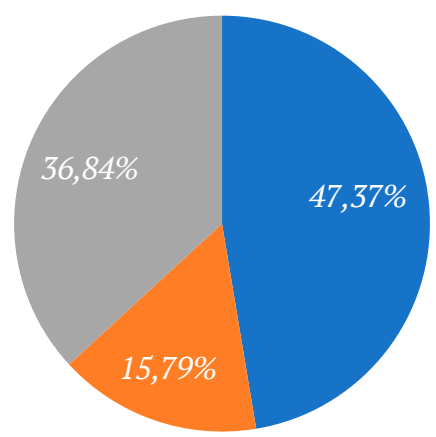


Finally, regarding the main differences they felt that existed when comparing online and face-to-face lessons, students highlighted again problems related to not feeling confident enough to speak in front of the computer, the artificial environment of the online class and technical problems they had to face, which is also in accordance with what was stated previous studies (Williams \& Carhill-Poza, 2020).

These results allow us to answer the two RQs that we established in the introduction of our paper. First of all, to answer RQ1, students highlighted technical problems as some of the main challenges, as well as not feeling completely comfortable in the online learning environment due to the lack of real communication, feeling shy and too many distractions at home which resulted in average results when asked about their level of satisfaction with their oral communication skills after taking the online class. This also had a consequence in the perception of their progress, since the majority felt that they had somehow missed out on some learning opportunities. In this regard, more attention should be paid by universities in general to solving the technical problems that students have been forced to deal with and also in providing teachers with training so as to tackle issues relating to boosting students' confidence when it comes to speaking in a foreign language in a virtual environment.

Regarding RQ2, students found that group video or audio calls were the most useful tools due to the communication component that enabled them to benefit from, followed by online games and materials. This is in line with what was stated by Destianingsih and Satria (2020) regarding the use of Google Classroom, which also allows students to use this kind of communication tools, or the study by Amuthan Krishnan et al. (2020) in which results showed how students perceived online materials such as those published in blogs as very useful to improve their language skills. However, only group video or audio calls were the most used tools by teachers, and online games and materials were not among their preferred options. This data could be of interest for future teaching considerations, since gamification has become a popular teaching methodology with many learning benefits that can be considered also in the online classroom and includes some of the key aspects highlighted by the respondents of our survey such as interaction and motivation.

\section{Conclusion}

The two aims of this paper were to analyse students' main challenges when communicating in English in an online setting as well as their perceptions about the tools and methodologies that worked best for them to enhance their oral skills. In order to answer the research questions associated with these aims, first of all in our introduction we reflected on the current situation of education and the changes that this pandemic has brought to it. In the theoretical framework we reviewed the most recent literature related to our topic of analysis, which allowed us to compare and contrast it with the results we obtained after distributing an online survey. These results were quantitatively and qualitatively analysed to provide a preliminary basis on what the main challenges that learning English online entails for enhancing students' oral skills in English. According to these results some of the main challenges students encountered were related to technological problems and the lack of real communication in the online environment, which they perceived as artificial. As for the main tools and methodologies, students found that group or audio calls, as well as gamified content were the ones that worked best of them, but they reported a lack of gamification techniques used by teachers in the virtual classes.

Although this is just a preliminary study on how the pandemic has had an impact on communication skills for students learning English as a second language, we believe that it provides an opportunity to challenge its status quo and explore and reflect on new approaches to the delivery of quality education in this regard. Regarding the limitations of the study, it must be said that the sample is limited and the study was only conducted in one university. However, we believe that this type of research studies are of special relevance in this period of time to educational developers and policymakers because it gives a preliminary understanding of aspects that can be considered to improve the efficacy of learners' and what teachers should consider in their virtual classes when it comes to enhancing English oral communication skills.

\section{Declaration of Competing Interest}

None declared. 


\section{References}

Alhabshneh, R., Alibrahim, A., Abu-Alteen, T., Hamadah, W., \& Khader, Y. Dental students' education in the era of Covid-19 pandemic: From reality to virtuality: Lessons to be learnt. Archives of Oral and Maxillofacial Surgery, 3. http://dx.doi.org/10.36959/379/356

Altam, S. (2020). Influence of social media on EFL Yemeni learners in Indian Universities during Covid-19 Pandemic. Linguistics and Culture Review, 4(1), 35-47. https://doi.org/10.37028/lingcure.v4n1.19

Altavilla, J. (2020). How technology affects instruction for English learners. Phi Delta Kappan, 102(1), 18-23. https://doi.org/10.1177\%2F0031721720956841

Bao, W. (2020). Covid-19 and online teaching in higher education: A case study of Peking University. Human Behavior \& Emerging Technologies, 2, 113-115. https://doi.org/10.1002/hbe2.191

Basilaia, G., Dgebuadze, M., Kantaria, M., \& Chokhonelidze, G. (2020). Replacing the classic learning form at universities as an immediate response to the Covid-19 virus infection in Georgia. International Journal for Research in Applied Science \& Engineering Technology, 8(3), 101-108. https://doi.org/10.22214/ ijraset.2020.3021

Crawford, J., Butler-Henderson, K., Rudolph, J., Malkawi, B., Glowatz, M., Burton, R., Magni P., \& Lam, S. (2020). Covid-19: 20 countries' higher education intra-period digital pedagogy responses. Journal of Applied Teaching and Learning, 3(1), 1-19. https://doi.org/10.37074/jalt.2020.3.1.7

Cutri, R. M., \& Mena, J. (2020). A critical reconceptualization of faculty readiness for online teaching. Distance Education, 41(3), 361-380. http://dx.doi.org.ezproxy.uned.es/10.1080/01587919.2020.1763167

Demuyakor, J. (2020). Coronavirus (Covid-19) and online learning in higher institutions of education: A survey of the perceptions of Ghanaian international students in China. Online Journal of Communication and Media Technologies, 10(3), e202018. https://doi.org/10.29333/ojcmt/8286

Dreamson, N. (2020). Online design education: Meta-connective pedagogy. International Journal of Art \& Design Education, 39(3), 483-497. http://dx.doi.org.ezproxy.uned.es/10.1111/jade.12314

Destianingsih, A. \& Satria, A. (2020). Investigating students' needs for effective english online learning during Covid-19 for polbeng students. ELT-Lectura: Studies and Perspectives in English Language Teaching, 7(2), 147153. https://doi.org/10.31849/elt-lectura.v7i2.4657

Fraenkel, J. R. \& Wallen, N. E. (2019). How to design and evaluate research in education. McGraw-Hill.

Gross, K. (2020). Can online learning be trauma-responsive? New England Journal of Higher Education. https:// search-proquest-com.ezproxy.uned.es/docview/2458993152?accountid=14609

Guillén, G., Sawin, T., \& Avineri, N. (2020). Zooming out of the crisis: Language and human collaboration. Foreign Language Annals, 53(2), 320-328. http://dx.doi.org.ezproxy.uned.es/10.1111/flan.12459

Gültekin, O., Erkaplan, S., Uzun, H., \& Güney, E. (2020). Investigation of academic staff's self-efficacy using the educational internet. Higher Education Studies, 10(3), 26-33. https://doi.org/10.5539/hes.v10n3p26

Hartshorn, K. J. \& McMurry, B. L. (2020). The effects of the Covid-19 pandemic on ESL learners and TESOL practitioners in the United States. International Journal of TESOL Studies, 2(2), 140-156. https://doi. org/10.46451/ijts.2020.09.11

Jang, I. C., \& Choi, L. J. (2020). Staying connected during Covid-19: The social and communicative role of an ethnic online community of Chinese international students in south Korea. Multilingua: Journal of CrossCultural and Interlanguage Communication, 39(5), 541-552. http://dx.doi.org.ezproxy.uned.es/10.1515/ multi-2020-0097

Kerres, M. (2020). Against all odds: Education in Germany coping with Covid-19. Postdigital Science and Education, 2(3), 1-5. https://dx.doi.org/10.1007\%2Fs42438-020-00130-7

Krishnan, I. A., Ching, H., Ramalingam, S., Maruthai, E., Kandasamy, P., Mello, G., Munian, S., \& Ling, W. (2020). Challenges of learning English in $21^{\text {st }}$ century: Online vs.traditional during Covid-19. Malaysian Journal of Social Sciences and Humanities, 5(9), 1-15. https://doi.org/10.47405/mjssh.v5i9.494.

Li, J., Xie, P., Ai, B., \& Li, L. (2020). Multilingual communication experiences of international students during the Covid-19 pandemic. Multilingua: Journal of Cross-Cultural and Interlanguage Communication, 39(5), 529-539. http://dx.doi.org.ezproxy.uned.es/10.1515/multi-2020-0116

MacIntyre, P. D., Gregersen, T., \& Mercer, S. (2020). Language teachers' coping strategies during the Covid-19 conversion to online teaching: Correlations with stress, wellbeing and negative emotions. System, 94, 102352. https://doi.org/10.1016/j.system.2020.102352

Mulenga, E., \& Marban, J. (2020). Is Covid-19 the gateway for digital learning in mathematics education? Contemporary Educational Technology, 12(2), 1-11. https://doi.org/10.30935/cedtech/7949

Myslihaka, L. (2016). Communication as the Center of Teaching/Learning Process of Foreign Languages (the 
case of French Language). European Journal of Multisdisciplinary Studies, 3(2), 147-154.

Park, C., \& Kim, D. (2020). Perception of instructor presence and its effects on learning experience in online classes. Journal of Information Technology Education: Research, 19, 475-488. https://doi.org/10.28945/4611

Perkins, K. (2020). Transforming STEM learning at scale: PhET interactive simulations. Childhood Education, 96(4), 42-49. http://dx.doi.org.ezproxy.uned.es/10.1080/00094056.2020.1796451

Perrotta, K., \& Bohan, C. H. (2020). A reflective study of online faculty teaching experiences in higher education. Journal of Effective Teaching in Higher Education, 3(1), 50-66. https://doi.org/10.36021/jethe.v3i1.9

Piller, I.; Zhang, J. \& Li, J. (2020). Linguistic diversity in a time of crisis: Language challenges of the Covid-19 pandemic. Multilingua, 39(5), 503-515. https://doi.org/10.1515/multi-2020-0136

Romero-Ivanova, C., Shaughnessy, M., Otto, L., Taylor, E., \& Watson, E. (2020). Digital practices \& applications in a Covid-19 culture. Higher Education Studies, 10(3), 80-87. https://doi.org/10.5539/hes.v10n3p80

Sahu, P. (2020). Closure of universities due to coronavirus disease 2019 (Covid-19): Impact on education and mental health of students and academic staff. Open Access Review Article, 14(12), 1-6. https://dx.doi. org/10.7759\%2Fcureus.7541

Sayer, P. \& Braun, D. (2020). The disparate impact of Covid-19 remote learning on English learners in the United States. TESOL Journal, 11(3), e00546. https://doi.org/10.1002/tesj.546

Wargadinata, W., Maimunah, I., Febriani, S. R., Humaira, L. (2020). Mediated Arabic language learning for higher education in Covid-19 situation. Izdiliar: Journal of Arabic Language Teaching, Linguistics, and Literature, 3(1), 59-78. https://doi.org/10.22219/jiz.v3il.11862

Wotto, M. (2020). The future high education distance learning in Canada, the United States, and France: Insights from before Covid-19 secondary data analysis. Journal of Educational Technology Systems, 49(2), 262-281. http://dx.doi.org.ezproxy.uned.es/10.1177/0047239520940624

Zaharah, Z. Kirilova, G. \& Windarti, A. (2020). Impact of coronavirus outbreak towards teaching and learning activities in Indonesia. SALAM: Jurnal Sosial dan Budaya Syar-i, 7(3), 269-282. https://doi.org/10.15408/ sjsbs.v7i3.15104

Zhang, W., Yang, Y., Wang, L., \& Yang, C. (2020). Suspending classes without stopping learning: China's education emergency management policy in the Covid-19 outbreak. Journal of Risk and Financial Management, 13(55), 1-6. https://doi.org/10.3390/jrfm13030055 


\section{Appendix 1}

Communication in English in online settings

Age Place of residence

Which tools did your teachers use to teach English remotely? (Tick all that apply)

Group video or audio calls (e.g. Zoom, Skype, etc.)

Recorded video and screencasts Slide presentations (e.g. PowerPoint)

Email

Phone calls

Social media (e.g. Facebook, Edmodo, etc.)

$\square$ Other

Which tools worked best to enhance your communication skills in English? (Tick all that apply) Group video or audio calls (e.g. Zoom, Skype, etc.)

Recorded video and screencasts Slide presentations (e.g. PowerPoint)

Email

Phone calls

Mobile phone messaging or app messaging

Online games and materials

Social media (e.g. Facebook, Edmodo, etc.)

Explain why the tools you chose in the previous question worked best for you.

How easy or difficult was it for you to communicate directly with your partners in your online English class?

(1 being very difficult and 5 very easy)

How easy or difficult was it for you to communicate directly with your teacher in your online English class?

(1 being very difficult and 5 very easy)

How confident were you to speak in class while taking online English lessons?

( 1 being not confident at all and 5 very confident)

What were the top three biggest challenges you faced while communicating in English in your online class?

Artificial online environment I was not used to

$\square \quad$ Feeling shy

$\square \quad$ Too many distractions at home

$\square \quad$ Technical problems

$\square \quad$ General anxiety about the coronavirus pandemic

$\square \quad$ Other

At the end of the semester, how satisfied were you with your oral communication skills in English after taking an online class?

( 1 being not satisfied at all and 5 being very satisfied)

Provide a justification for your previous answer.

Did you feel that with online English lessons you missed out on some learning opportunities to enhance your communication skills?

No $\quad \square$ Yes $\quad \square$ Maybe 


\section{ONLINE LEARNING DURING THE COVID-19 PANDEMIC}

Provide a justification for your previous answer.

What were the main differences that you experienced while taking online English lessons compared to faceto-face learning regarding your oral communication skills in English?

Is there anything else you would like to tell us in relation to your experience learning English in an online environment? 